\title{
Arte estatuario en Chile durante la primera mitad del siglo XX: Del monumento público a la escultura ${ }^{1}$.
}

\author{
Pedro Emilio Zamorano Pérez $\left(^{*}\right)$ \\ Claudio Cortés López $(* *)$ \\ Francisco Gazitúa Costabal (***)
}

\begin{abstract}
RESUMEN
Este trabajo aborda el desarrollo del arte estatuario en Chile a partir de las relaciones entre los artistas nacionales y las escuelas europeas, en donde la mayor parte de ellos estudia. Entrega información respecto de los arquetipos artísticos e iconográficos más usados en nuestro país en la escultura de fines del siglo XIX y acerca de la declinación del modelo clásico que se produce durante las primeras décadas del siglo XX. Proporciona también información sobre los nuevos conceptos escultóricos que se establecen en el país, ahondando en la obra de algunos artistas locales que lideran este proceso de innovación estética en nuestro medio.
\end{abstract}

Palabras clave:

Escultura chilena - modelo clásico - innovación escultórica - artistas principales.

\footnotetext{
${ }^{*}$ ) Doctor en Historia del Arte, Universidad Complutense de Madrid, España. Académico del Instituto de Estudios Humanísticos de la Universidad de Talca.

(**) Magíster en Teoría e Historia del Arte. Académico de la Universidad de Chile. Coautor.

${ }^{(* *)}$ Escultor. Coautor.

Artículo recibido el 8 de marzo de 2011. Aceptado por el Comité Editorial el 20 de mayo de 2011.

Correos electrónicos: pzamoper@utalca.cl

c.cortes@uchilefau.cl

gazituafrancisco@gmail.com

${ }^{1}$ Este artículo se inserta en el proyecto "Escultura chilena 1854-1960: el trasluz de su identidad", Fondecyt No 1085295. Investigador Responsable, Pedro Emilio Zamorano.
} 


\begin{abstract}
This work deals with the development of the art of statues in Chile starting from the relations between the national artists and the European schools, where most of them study. It provides information about the artistic and iconographic archetypes mostly used in our country in the sculpture at the end of XIX century and about the declination of the classical model produced during the first decades of XX century. It also provides information about the new sculptural concepts established in the country, deepening in the work of some local artists that lead this process of innovation aesthetic in our circles.
\end{abstract}

Key words:

Chilean sculpture - classical model - sculptural innovation - main artists.

\title{
Antecedentes
}

La formación de escultores en nuestro país tuvo un espacio casi hegemónico: la Escuela de Bellas Artes de la Universidad de Chile. Allí estudiaron los artistas bajo concepciones técnicas y estéticas que, en lo fundamental, no han variado, es decir, bajo los paradigmas de los artistas estatuarios. Ello ocurrió desde las primeras promociones de escultores, a quienes Víctor Carvacho ha llamado como del bello estilo $^{2}$, hasta aquellas generaciones que egresan en los años sesenta de la pasada centuria.

Del director y maestro inicial de la enseñanza de la escultura en nuestro país, el francés Augusto François (1814-1896), hay escasos antecedentes biográficos y pocas obras que sirvan de referencia ${ }^{3}$. Su aporte fue el haber iniciado la enseñanza del arte estatuario en Chile bajo una formalidad académica. En 1854 se crea bajo su dirección la Escuela de Escultura Ornamental en Relieve. Se trataba de una entidad para preparar artesanos, que funcionaba en la sacristía de la Capilla de la Soledad, al lado del convento de San Francisco. Un decreto del Departamento de Justicia, Culto e Instrucción Pública del Supremo Gobierno, de 24 de mayo de 1854, dio inicio y estructura académica a esta actividad en Chile y nombró a su director. Es posible que los objetivos iniciales y la propia noción de escultura previstos por las autoridades de la época, que toman la decisión de fundar la entidad, hayan concebido al arte estatuario más cerca de la funcionalidad artesanal que de criterios y exigencias estéticas. En el referido Decreto de 1854 esta situación queda más o menos explícita: “Que el aprendizaje del dibujo lineal no puede ofrecer todo el provecho de que es susceptible, para los constructores de edificios i ebanistas, como para los que se consagran a otras artes $u$ oficios con que aquel tiene relación, si el artesano no se haya capaz de ejecutar en relieve lo que

${ }^{2}$ Carvacho señala en esta categoría a José Miguel Blanco, Nicanor Plaza y Virginio Arias.

${ }^{3}$ En los escasos datos aportados por el Diccionario Benezit, se le señala como discípulo de David d'Angers y de Rude, además de consignar alguna participación suya en los salones de París de 1848 y 1849. De sus obras más conocidas en Chile apuntamos la escultura del Abate Molina, ubicada en la Alameda de Talca y que fuera fundida en la Escuela de Artes y Oficios de Chile, por Juan E. Silva en 1861. 
aprende a dibujar, adquiriendo principios elementales de escultura". En el hecho se establece en el propio documento de creación, que se trata de una escuela de escultura ornamental y dibujo de relieve para artesanos. Estos conceptos de funcionalidad del arte estatuario, usado también en la época para el diseño de monedas u otros objetos ornamentales, relevan una noción de funcionalidad, uso y supeditación iconográfica. Además, involucran una valoración del bien hacer técnico, del virtuosismo del oficio. En este sentido en la escultura, sea ella concebida bajo la lógica del modelado (arte aditivo) o de la talla (sustrativo), siempre ha pesado el oficio del escultor, el que, a diferencia de la pintura, varió poco desde las expresiones escultóricas más antiguas hasta aquellas que se desarrollan en la medianía de la pasada centuria. La manualidad artesanal, el bien hacer técnico, estuvo siempre en la esencia del arte del volumen; ha sido un punto de encuentro de teorías y visiones, de distintos lenguajes escultóricos, de la tradición y la vanguardia en esta expresión artística ${ }^{4}$. La calidad del oficio, en todo caso, estará siempre al servicio del discurso creativo; de ningún modo servirá, como señala Sauras (2003, p. 41) para acartonarse en su sombra. También es necesario considerar que la técnica no representa un valor en sí mismo, su ponderación excesiva puede llevar a resultados vacuos y carentes de creatividad y poesía.

\section{Influjos y transferencias ${ }^{5}$}

Las artes y en general la cultura chilena ha estado atravesada por vínculos con modelos foráneos, principalmente europeos. Distinguimos aquí dos fenómenos que operan tanto en el espacio cultural como en el soporte formal e iconográfico de las obras artísticas. El primero de ellos, los influjos, se manifiestan en un contexto cultural amplio, no exclusivamente acotado al fenómeno estético, y actúan también en otras facetas tales como la literatura, moda y la arquitectura. Las transferencias, por su parte, estimamos, se manifiestan al interior del discurso estético y operan en la obra artística bajo la modalidad de extrapolaciones formales, conceptuales y técnicas.

$\mathrm{Al}$ analizar algunas esculturas chilenas, ubicadas tanto en el espacio público como en museos, constatamos la presencia de estos vínculos, transferencias e influjos, que escenifican una relación con ideas y concepciones estéticas foráneas. Tal situación puede ser advertida no sólo en los textos teóricos, sino que también a partir del análisis de las propias obras. De este modo vemos que los modelos estéticos que se presentan con más fuerza en el arte nacional portan el ADN de algunas escuelas europeas, tales como la francesa y la italiana. La pintura y la estatuaria nacional testimonian tal situación. Esta semejanza estética puede operar como apropiación, integración o sumatoria a un determinado estilo, movimiento, escuela, y en algunos casos más específicos, como asimilación a un discurso estético individual.

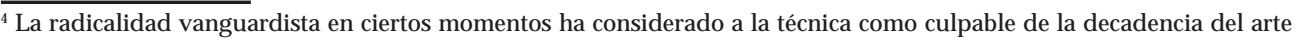
anterior. Señalaron como pompiers a los artistas de oficio académico a la vez que denostaron a los salones oficiales y a las escuelas tradicionales de bellas artes.

${ }^{5}$ Los autores de este artículo han desarrollado los conceptos de "influjos" y "transferencias" en diferentes proyectos de investigación, financiados por FONDECYT. Ellos son "Influencias europeas en la pintura chilena durante la primera mitad del siglo XX" ( $\left.\mathrm{N}^{\circ} 1960225\right)$, "El desarrollo de la crítica de arte en Chile a partir de la obra hemerográfica de Antonio Romera" ( $\left.\mathrm{N}^{\circ} 1010591\right)$, “Asedio exógeno a la pintura chilena: 1920-1960" ( $\left.\mathrm{N}^{\circ} 1040858\right)$ y “Escultura chilena 1854-1960: el trasluz de su identidad" ( $\left.\mathrm{N}^{\circ} 1085295\right)$.
} 


\section{Identidad contradictoria: inadecuación entre forma y contenido}

La mitología y lo narrativo han sido referentes iconográficos importantes en el arte escultórico en nuestro país durante la segunda mitad del siglo XIX y en los años iniciales del XX. Además de estos contenidos temáticos es posible constatar también la reedición de algunos conceptos formales y técnicos de raigambre clásica, tales como la proporcionalidad (canon), gestos, materiales y tradiciones técnicas relacionadas con el modelado, la talla y la fundición de obras. Estos modelos y concepciones estéticas no siempre estaban en armonía con los signos y las demandas del espacio local. En muchas de las esculturas realizadas en esta época encontramos una fuerte inadecuación entre la forma y el contenido, entre el modelo clásico concebido bajo el canon helénico y su representación y vinculación con los personajes nacionales representados. Radoslav Ivelic (2001, p. 154) fundamenta esta asimetría a partir de la obra de Virginio Arias El defensor de la patria (1884), más conocida como El roto chileno, ubicado en la Plaza Yungay de Santiago. La obra reproduce el arquetipo "policlético", esto es la cabeza como una séptima parte del cuerpo, un rostro inexpresivo y helenizante, una leve sinuosidad del cuerpo como consecuencia del quiebre de la cadera (contraposto) e, incluso, un apeo innecesario en su base, toda vez que se trata de un bronce y no un mármol. Nos encontramos aquí ante una identidad contradictoria, que desarrolla una temática autóctona a partir de un modelo estético cultural ajeno. Otros numerosos ejemplos de esta asimetría los encontramos en algunas representaciones de nativos realizadas por escultores nacionales. Quizá el más conocido sea El Caupolicán, de Nicanor Plaza. Esta obra recoge relictos de la estética helenística, que recuerdan el escorzo del Laocoonte, además de conceptos barrocos cercanos al David de Gian Lorenzo Bernini. José Miguel Blanco, por su parte, fue el autor un par de obras con el tema indígena, El Galvarino y El padre Bartolomé de las Casas amamantado por una indígena; Virginio Arias realizó, también, Madre araucana. Estas obras contrastan, por ejemplo, con las representaciones indígenas tan cargadas de color local, que hiciera décadas después la boliviana Marina Núñez del Prado, quien a decir de Gabriela Mistral (1961, p.19) “Ha puesto toda su obra prodigiosa a la empresa de sacar a la luz la desventura secular del indio".

La impronta de la cultura académica europea estaba todavía fuertemente instalada en nuestro medio durante la segunda mitad del siglo XIX y hasta las décadas iniciales del XX. En ella se veía reflejada la sociedad chilena influyente. El Estado, organizador principal del campo cultural local, pesaba con su mirada en las decisiones en casi todos los ámbitos de la actividad. La institucionalidad cultural controlaba los circuitos de formación, circulación y ventas de obras. Había, de igual modo, voces teóricas y medios que se hacía parte de este discurso, adhiriendo al paradigma clásico ${ }^{6}$.

\section{La esclavitud de lo literario y lo histórico}

Desde antiguo, la literatura, en sus más variadas facetas, condicionó la iconografía

\footnotetext{
${ }^{6}$ Durante el siglo XIX encontramos escritos de Alejandro Cicarelli Discurso de Inauguración de la Academia de Pintura en 1849), de José Miguel Blanco, Paulino Alfonso, Ignacio Domeyko, Emilio y Manuel Rodríguez Mendoza, Marcos Maturana, Pedro Lira, Arturo Blanco, Enrique Nercaseaux Morán, Vicente Grez y Virginio Arias, entre otros. En los inicios del siglo XX tenemos a Ricardo Richon Brunet, Nathanael Yáñez Silva, entre otros.
} 
de la pintura, la escultura y hasta la arquitectura. El libreto artístico de la Academia de Pintura de Chile, creada por Alejandro Cicarelli en 1849, al igual que la posterior clase de escultura de François, tuvieron un sello literario e historicista y una filiación con el panteón heleno. No se trata sólo de una adhesión ciega a la cultura clásica. Quizá la explicación debamos buscarla en los propios contenidos de enseñanza de las entidades de formación de artistas que se inauguraban. Allí se ejercitaba a los estudiantes sobre la base de modelos clásicos, dibujándolos y reproduciéndolos en volumen. La iconografía clásica, el tema histórico y, en menor medida, ciertos asomos de un romanticismo, con tintes realistas, se correlacionan también con la mirada de la elite dirigente y con quienes detentan poder en el espacio cultural. Las abundantes alusiones al mundo griego que encontramos en el discurso pronunciado por Cicarelli cuando se funda la Academia de Pintura tenían sentido en una sociedad que se auto percibía como europea y que pensaba que allí radicaban los contenidos de su discurso progresista. Alberto Mackenna Subercaseaux, actor de primera línea en la oficialidad cultural en el Chile del Centenario, declara su filiación al paradigma en sus argumentos para traer e nuestro país un museo de copias de esculturas clásicas. "¡Cómo pudiéramos llevar a Chile una muestra siquiera de las maravillas del arte antiguo! ¡Cómo dar a conocer a todos los nuestros la Venus cincelada de Praxíteles, el Moisés de Miguel Ángel, el Gladiador moribundo, el Descendimiento de Bernini, el San Juan del Donatello, el Apolo Citaredo y tantas otras obras de suprema belleza que se exhiben en los museos de Roma". Consideraciones de esta naturaleza instalan en Chile la singular idea de que ser clásico es sinónimo de ser moderno. Una idea peregrina de concebir la modernidad más bien como una "puesta a tono", una sintonía con los espacios conservadores europeos.

\section{Escultura y emplazamiento}

El entorno que se decide como destino definitivo para una escultura, es decir su emplazamiento, es parte del discurso estético y formal de la obra. No es lo mismo ubicar una obra en espacio interior o exterior, abierto o cerrado, urbano o rural. A decir de Javier Sauras (2003, p. 41) la presencia de una obra escultórica añade al espacio que la enmarca muchas cargas emocionales que hay que saber prever e imaginar. Para algunos la arquitectura y el paisaje resultan ser aliados naturales de la pieza escultórica. En el tradicional monumento público, que pobló la ciudad americana decimonónica, entendemos que la escenografía de la ciudad, los edificios y los elementos de circulación urbanística, condicionan el sentido y el contenido de la obra escultórica. En ese contexto la escultura se posiciona en un espacio simbólico y desde allí ejerce su programa de información. A decir de Javier Maderuelo (1994, p. 48) el monumento público es uno de los signos ideológicamente más alabado en la semiótica de la ciudad. Otras visiones, más contemporáneas, discrepan de tales aseveraciones. Desde un inmanentismo estético más radical estiman que la arquitectura y el paisaje pueden llegar a ser elementos discrepantes e incluso perturbadores de la obra. Que la escultura debe ejercer su autonomía por sí misma. En esta relación de escultura, arquitectura y ciudad, los edificios han ido reemplazando esa capacidad referencial que tenían los monumentos escultóricos en el espacio público. De este modo, en algunas ciudades han pasado a ser las construcciones los hitos significativos de su 
desarrollo urbano.

\section{Vigencia y declinación del modelo clásico}

La instalación en Chile del modelo clásico queda definida ya en los planes y programas de las primeras instancias de formación artística en el país. Como se ha señalado, la Academia de Pintura, creada bajo el gobierno de Manuel Bulnes, tuvo por principios, en lo que se refiere a argumentos plásticos y simbólicos, las normas de la cultura grecorromana ${ }^{7}$. Situación similar ocurrió con la enseñanza de la escultura. Además, muchos de los artistas chilenos formados en la Escuela de Bellas Artes continuaron sus estudios en Europa. Hubo, podríamos decir, una política de Estado que llevó a los pintores y escultores, principalmente a París. El modelo de las academias europeas, francesas e italianas principalmente, fue tomado al pie de la letra en nuestro país. La École Nationale des Beaux-Arts fue, de este modo, el lugar más apreciado para la formación de los artistas nacionales. Cuando se analiza el reglamento de esa entidad francesa, publicado en $1908^{8}$, se advierten muchas similitudes con los modelos y conceptos que se enseñaban en nuestro país ${ }^{9}$. La escultura clásica y su enseñanza respondían a unas reglas concretas que se expresan a través de la representación pitagórica de los cánones, los que tienen su expresión y medida en la figura humana. A decir de Javier Maderuelo (1994, p.16) estas normas, usadas por los escultores clásicos, buscaban la representación armónica del cuerpo y expresan ideas y conceptos de carácter filosófico. "Responden a formulaciones retóricas que pueden ser rastreadas en las ideas de los filósofos que, como Aristóteles o los pertenecientes a las escuelas estoicas o epicúrea, se preocuparon por los problemas formales en la poesía y en las artes".

En esta valoración iconográfica del mundo clásico es necesario relevar también el aporte de algunos historiadores e intelectuales. El más conocido fue Johann Joachim Winckelman (1717-1768). En una de las primeras publicaciones de este autor, Reflexiones sobre la imitación de obras griegas en pintura y escultura (1755) se pretendía no solo recuperar el pasado helénico, sino que mantenerlo en vigencia como parámetro para la estética de su momento histórico. “El único camino que se nos abre para hacernos grandes, o mejor dicho, y si es posible, inimitables, es la imitación de los antiguos"10. De otra parte, de los filósofos de finales del siglo XVIII y comienzos del XIX, dedicados a la estética, será Georg W. F. Hegel (1770-1831) el que se introdujo con mayor profundidad en la fenomenología de la estatuaria griega. El trabajo

\footnotetext{
7 Véase el discurso de Alejandro Cicarelli en la Inauguración de la Academia de Pintura (7 de marzo de 1854), referido en Artes plásticas en los Anales de la Universidad de Chile, por Rosario Letelier y otros. Museo de Arte Contemporáneo, 1993.

${ }^{8}$ Règlement Ècole Nationale des Beaux - Arts, Ministère de L'Instruction Publique des Beaux - Arts et des Cultes, Delalain Frères Èditeurs, París 1908

${ }_{9}^{9}$ A modo de ejemplo, la parte teórica fue importante tanto en la Ècole, como en la Escuela de Bellas Artes chilena. En la Ècole, cada año, los artistas cursaban los siguientes ramos: Historia y Arqueología, Historia General, y Literatura, cursos que se desarrollaban a los largo de tres años. También fueron relevantes los cursos de Historia del Arte y Estética.

La expresión más consagratoria en la época para los artistas franceses era la obtención del Premio Roma. Varios países europeos, entre ellos Francia y España tenían respectivas academias en la Ciudad Eterna. La academia francesa en Roma, situada en la Villa Médicis, en los jardines de la Villa Borghese, en el Pincio romano, era el destino para aquellos artistas que obtenían en Francia el Premio Roma, que consistía en una beca de cinco años. Algunos artistas que obtuvieron la distinción fueron el pintor Raimundo Monvoisin y Denys Puech, quien dirigió la entidad entre 1921 y 1933.

${ }^{10}$ Mencionado por Rudolf Wittkower en La escultura procesos y principios, p. 252.
} 
realizado por este pensador alemán es de especial importancia debido a sus análisis de los sistemas constructivos de la figura humana. A este respecto señala (1985, p. 143): El centro de nuestra consideración será dado según lo dicho, a la manera en que lo ideal clásico alcanza a través de la escultura, su más adecuada realidad. Pero antes de poder pasar a este desarrollo de la escultura ideal, debemos primero mostrar qué contenido y qué forma conviene estrictamente al punto de vista de la escultura, como arte particular, y la conducen, en consecuencia, a representar el ideal clásico en la figura humana espiritual animada y su forma abstracto espacial ${ }^{11}$. Las producciones escultóricas, su enseñanza, los modelos y repertorios iconográficos son influenciados por estas ideas, que se institucionalizan en el espacio de las academias oficiales, los sectores oligárquicos y la crítica más conservadora.

En Chile, obras tales como Giotto, de Carlos Lagarrigue, Hoja de Laurel y Dafne y Cloe, ambas de Virginio Arias, La quimera, de Nicanor Plaza, Horacio, de Rebeca Matte y Alegoría de las Bellas Artes, de Guillermo Córdova, constituyen ejemplos interesantes de esculturas realizadas por nuestros artistas en donde es posible seguir la huella de lo grecolatino. Se trata de obras cuyos modelos y dimensiones semánticas fueron planteadas inicialmente por la estatuaria griega del siglo V al II a.C., continuadas por la cultura romana y reinterpretada por el Renacimiento, especialmente en su manifestación italiana. Estos códigos clásicos y helenísticos se ponen de manifiesto en nuestro medio bajo diferentes categorías, las cuales van desde la copia, los préstamos formales y las re-interpretaciones.

Hacia fines del siglo XIX, la escultura chilena comienza a incursionar en otros espacios iconográficos. Aparecen algunos temas relacionados con la estética romántica, además de una línea adscrita al realismo. Habría que sumar también aquellas obras de carácter ecléctico que inscriben en su planteamiento la combinación de diferentes discursos estéticos. En este sentido, la dualidad realismo-romanticismo pareciera ser una de las constantes estéticas más recurrentes en nuestro medio. Algunas obras como La miseria, de Ernesto Concha y El mendigo de Simón González, pueden constituir buenos ejemplos de lo expresado precedentemente.

Si el romanticismo, entre otros aspectos, puede entenderse como la ausencia de tranquilidad, el sentimiento del dolor y una especie de intensidad que, a decir de Sourieau (1998, p. 968) une lo trágico con lo grotesco, la exaltación del sentimiento, como un diálogo entre las intenciones del artista y la obra como proceso y resultado, son conducentes en estos casos a ponderar la infelicidad como argumento estético. Por su parte, el realismo, entendido como una acuciosa examinación del entorno más directo, se propuso transcribir aquello observado y ponerlo en el escenario de lo estético. Las líneas de acción en esta búsqueda de lo testimonial son varias. Una de ellas tiene que ver con el mundo de los más desvalidos, ello con toda la desgracia y fatalidad que este asunto conlleva. El pensamiento filosófico y estético de Pierre Joseph Proudhon se vincula con esta línea del realismo. Sus ideas y experiencias de vida le otorgaron consistencia teórica a la corriente realista en general y, en especial, a la pintura dedicada a la representación del proletariado. En el capítulo XIII de su libro

\footnotetext{
${ }^{11}$ Hegel, W. F. Estética, “La arquitectura y la escultura”. Ediciones Nueva Visión, 1985, p. 143.
} 
Sobre el principio del arte Proudhon señalaba; "Pintar a los hombres dentro de la sinceridad de su naturaleza y de sus costumbres, en sus trabajos, en el cumplimiento de sus funciones cívicas y domésticas, con su fisonomía actual, sobre todo sin pose; sorprenderlos, por decirlo así, en la intimidad de sus conciencias, no simplemente por el placer de burlarnos, sino con una finalidad de educación general y a título de advertencia estética" ${ }^{12}$. La búsqueda de la objetivación lleva también al escultor a poner en escena las alteraciones óseas y musculares producto del envejecimiento o de las patologías asociadas al devenir biológico del ser humano. En este sentido, la expresión de El mendigo, realizado por el escultor chileno Simón González se encuentra dada principalmente por la decadencia carnal, en donde la flacidez y las texturas de una piel ajada, pueden observarse como una narración; la vejez y decadencia física transporta un sentido social: el desamparo. En La miseria, de Ernesto Concha, la deformación de los pies del personaje mayor (juanetes muy evidenciados), las vestimentas, las actitudes y las expresiones de los rostros, ocupan un lugar de preeminencia, ello en tanto contenido sensible de un discurso que asocia lo ético con lo estético. En estas obras los intereses de ambos escultores apuntan a elementos comunes, como también a situaciones que los diferencian. Los une la orientación social de las fisonomías de sus modelos, como también las tipologías de hombres y mujeres insertos en la indigencia. Los separa el realismo crudo de González, versus el realismo transfigurado, de Concha. En el primero se observa una consignación gestual y expresiva que caracterizan a un menesteroso. En el segundo caso vemos la actitud dramática y teatral de la figura femenina mayor, que contrasta con las circunstancias que presenta la figura más pequeña. Se agrega a esta última obra, el movimiento centrífugo de los ropajes, que recuerda la escultura barroca italiana y francesa.

El espacio de formación, circulación y difusión del arte estaba en Chile muy acotado a las directrices de la Escuela de Bellas Artes y a ciertas instancias tutelares, como el Consejo de Bellas Artes. Como señala Patricio Lizama (1992, p. 11) Podemos notar que el arte académico no era solamente una determinada expresión plástica a la cual adherían los artistas por percepciones pictóricas definidas, sino que era un verdadero sistema autosuficiente en su producción, recepción y legitimidad, que reproducía los gustos y percepciones de la clase dirigente. El artista que optaba por el arte académico, elegía una alternativa que le otorgaba estudios, salones, premios, medallas, viajes, crítica favorable, reconocimiento social y económico. Estas circunstancias y la propia legitimidad del modelo clásico impedían que la innovación artística, que había irrumpido en Francia con el Impresionismo, tardara todavía varias décadas en llegar a Chile. El modelo clásico gozará de buena salud todavía por largos años en nuestro país. Su mutabilidad dice relación, en el terreno de la escultura, con la presencia de una iconografía de sensibilidad romántico realista que se da hacia fines del siglo XIX. Este debilitamiento clasicista se hace todavía más evidente con el advenimiento del nuevo siglo; al quiebre temático propuesto por los pintores de 1913, advienen los ecos de la vanguardia artística europea y, con ello, una objeción directa a los modelos estéticos decimonónicos. El testimonio más consciente de innovación lo encontramos

${ }_{12}$ P. J. Proudhon, Editorial Aguilar, p. 203. 
en el grupo Montparnasse ${ }^{13}$, quienes en su primera exposición plantean un cambio más o menos definitivo con las tradiciones académicas del siglo XIX. Otro momento que dinamizó el debate en la escena local fue el Salón de 1928. Los desacuerdos y mutuas descalificaciones expresados allí entre aquellos que defendían las premisas académicas y aquellos que enarbolaban los fundamentos de la razón plástica, habían llegado a un punto insostenible. Influyen también en la agitación de la escena estética local las transformaciones introducidas en la Escuela de Bellas Artes por el gobierno del general Carlos Ibáñez del Campo (1927-1931), quien da a su gestión un carácter dictatorial, fundacional y nacionalista. Un nacionalismo que, a decir de Patricio Lizama (2001, p. 139) advertía dos dimensiones del arte. Una tenía relación con las proyecciones económicas y significaba que el trabajo creador debía transformarse en algo útil, puesto al servicio del desarrollo económico del país. Otra era su componente ideológico. Según el gobierno, existía una decadencia en el sentido de nacionalidad y en la valoración de los rasgos del carácter chileno. Se plantea aquí la necesidad de articular una identidad, un alma basada en la esencia inconmovible que tenía sus raíces en los antepasados indígenas. Estos objetivos podían viabilizarse en el contexto educacional y para ello resultaba inevitable intervenir la Escuela de Bellas Artes. El encargado de conducir el proceso de cambio en la entidad fue el pintor Carlos Isamitt, quien asumió la dirección en 1927. Interesaba al gobierno terminar con la imitación de los modelos foráneos, y rescatar y elaborar creativamente el patrimonio local e indígena ${ }^{14}$. En este contexto intervino el gobierno, quien a través de su ministro de Instrucción Pública, Pablo Ramírez, decidió cerrar la Escuela de Bellas Artes y enviar a estudiar a Europa a veintiséis de los más destacados alumnos y profesores del plantel ${ }^{15}$. Se mandó, de este modo, a parte importante de los artistas nacionales al Viejo Mundo, fijándosele a cada cual un itinerario de perfeccionamiento. Este consideraba el conocimiento de aspectos prácticos, teóricos y metodológicos para la enseñanza del arte, con expresa indicación de los países en que se debían cursar los estudios $^{16}$. De los veintiséis nombres que integraron la nómina ${ }^{17}$, menos de la mitad de los becados tuvo a su regreso cierta significación artística. Los restantes nombres se nos presentan, en esta perspectiva de tiempo, o como ilustres desconocidos, o como artistas de una muy menguada significación. El envío de estos artistas a Europa, en

\footnotetext{
${ }^{13}$ La primera muestra del grupo se produjo en el mes de junio de 1923, en la Casa de Remates "Rivas y Calvo" de Santiago. Integran el grupo los pintores Luis Vargas Rosas (1897-1977), Enriqueta Petit (1900-1984), Julio Ortiz de Zárate (1885-1946), Manuel Ortiz de Zárate (1887-1946), Augusto Eguiluz (1893-1969), José Perotti ((1898-1956), Jorge Letelier (1887-1996), Hernán Gazmuri (1901-1979), Camilo Mori (1896-1973), Jorge Caballero (1902-1992), Waldo Vila (1896-1979) e Isaías Cabezón (1891-1936).

${ }^{14}$ Por esta época llegan a la entidad dos nuevos profesores, el pintor ruso Boris Grigorief y Ricardo Latcham, quien dictaba las clases de Arte Primitivo Nacional y Latinoamericano.

${ }^{15}$ Decreto Supremo, del 5 de marzo de 1929.

${ }^{16}$ A modo de ejemplo: a Camilo Mori Serrano se le encargó estudiar "Pintura y cerámica, organización de museos, Academias y Escuelas de Artes Aplicadas, debiendo desempeñar, además, el cargo de Inspector de Estudios, en Europa en general, con dieciocho mil pesos (\$18.000)"; a Julio Ortiz de Zárate "Vaciado, modelaje y ornamentación plástica (Talla en piedra y madera) en Francia y Alemania, con \$15.000"; a Armando Lira "Aplicación del dibujo a las artes industriales, diferentes métodos de la enseñanza del dibujo y pintura en las distintas ramas de la educación. Cursos de formación y perfeccionamiento de profesores de dibujo y pintura en Francia e Italia, con diez mil ochocientos pesos (\$10.800)", etc. El decreto consideraba también perfeccionar a los artistas en escultura, artes aplicadas y pintura mural, entre otras técnicas y disciplinas.

${ }^{17}$ La nómina de becados fue la siguiente: Jorge Madge Cortés, Julio Ortiz de Zárate, Camilo Mori Serrano, Isaías Cabezón Acevedo, Emilia Ladrón de Guevara Romero, Julio Vázquez Arriagada, Luis Vargas Rosas, Oscar Millán Valdovinos, Graciela Aranis Valdivia, Héctor Banderas Cañas, Gustavo Carrasco Délano, María Valencia Díaz, René Meza Campbell, Héctor Cáceres Osorio, Teresa Miranda, Laura Rodig Pizarro, Armando Lira, Laureano Ladrón de Guevara Romero, Abelardo Bustamante, Roberto Humeres Solar, Ignacio del Pedegral Corvalán, Inés Puyó León, Augusto Eguiluz, Marcial Lama Rojas, y Rafael Alberto López.
} 
el contexto de esta cruda y excéntrica intervención estatal, no redituó a la cultura nacional todos los beneficios que se esperaba de ella.

Por su parte, la crítica de arte tuvo un papel importante en este proceso de innovación, especialmente en la legitimación de los nuevos referentes artísticos en el país. El escenario teórico estuvo marcado por voces conservadoras y plumas rupturistas ${ }^{18}$.

La reflexión teórica se había diversificado con el aporte de literatos e intelectuales, quienes ejercían su función en distintos medios escritos ${ }^{19}$. El antagonismo que se produce entre conservadores y vanguardistas tiene por protagonistas, de una parte, a aquellos artistas identificados con el Consejo y la Escuela de Bellas Artes y con la crítica más conservadora; $y$, de otra, a los artistas más jóvenes, liderados por Juan Francisco González, quienes se agrupan en la Sociedad Nacional de Bellas Artes, creada en 1918, entidad cuyo signo contestatario la transforma en alternativa de los esquemas académicos tradicionalistas que todavía tenían cierto peso en el país. Como señala Alejandro Canseco-Jerez (2001, p. XIV), se erigen dos bandos, aquellos que le exigen al arte y la literatura que se ponga al servicio de las grandes ideas (nación, patria, cultura, identidad) y los que reclaman una entera libertad basada en criterios intrínsecamente estéticos. Todo esto abrirá a la cultura chilena, en las artes visuales y la literatura en particular, hacia caminos inexplorados.

\section{Las nuevas formas escultóricas}

En los inicios del siglo XX la demanda sobre obras escultóricas procedía principalmente de la esfera pública. El problema fue, como señala Hobsbawm (1999, p. 18), que colapsó el mercado de su principal producto: el monumento público. La renovación de la escultura, tema que se venía planteando ya en Europa desde la segunda mitad del siglo XIX, modificó, primero, los sustentos formales e iconográficos de las obras, luego, el propio sentido del arte del volumen. La revisión, o incluso negación, de algunos principios que habían caracterizado el género escultórico clásico, el cambio de repertorios temáticos, formales, medios expresivos, llevan al arte del volumen a territorios inexplorados, más desahogados en la exigencia creativa. Dentro de los muchos cambios que se plantean en este sentido está la propia ubicación de las esculturas. El tradicional monumento conmemorativo asociaba su prestigio e importancia a una ubicación preeminente en el espacio público. De este modo, la obra podía dotar de un significado o convertir en hito a ciertos lugares de la ciudad. Otro elemento que declina su importancia, ya en los años iniciales del siglo XX, fue el pedestal. Esta estructura arquitectónica tenía como misión elevar la obra del suelo a la vez que subrayar su valor simbólico. Obras tales como Homenaje a Hernando de Magallanes, de Guillermo Córdova, en Punta Arenas, el Homenaje a los héroes de Iquique, de Denys Puech, en Valparaíso y la Escultura ecuestre a Bernardo O`Higgins, de Carriere Belleuse, en Santiago, ilustran acerca de la importancia que tuvo el pedestal en los monumentos públicos emplazados en nuestro país. Augusto Rodin

\footnotetext{
${ }^{18}$ Las plumas más influyentes en el proceso de innovación del arte chileno fueron Álvaro Yáñez Bianchi (Jean Emar) y Vicente Huidobro.

${ }^{19}$ Desde la revista del grupo Los Diez (1916-1917), la revista Juventud y la revista Claridad comienzan a objetarse las normas académicas, a la vez que a valorarse las tendencias emergentes.
} 
marca en este sentido un cambio. En su Monumento a Balzac, fundió la escultura y el pedestal en un único bloque, indiferenciado, marcando de este modo un camino de autonomía estética para la obra. Similares actitudes encontramos en algunas obras de Constantino Brancusi y Alberto Giacometti. A decir de Maderuelo (1994, p.19) La pérdida del pedestal en la escultura moderna refleja la ausencia de voluntad conmemorativa y, como consecuencia, evidencia el carácter efímero que se opone a la noción de permanencia que caracteriza a la escultura tradicional.

Otro rasgo que señala un cambio en la escultura chilena es el alejamiento de algunos artistas del uso de aquellos medios expresivos considerados tradicionalmente como nobles. La madera, el hierro, el cemento, el granito y otras piedras reemplazan casi en su totalidad al mármol y el bronce. A esta renovación de materiales debemos sumar la transformación, quizá, más importante del arte escultórico en Chile durante las primeras décadas de la pasada centuria; se trata de la innovación temática y del alejamiento de los modelos clásicos. Como hemos visto la escultura decimonónica en nuestro país había tratado, en forma casi exclusiva, el tema del cuerpo humano. En este sentido la escultura sigue los pasos de la pintura que partió su proceso de innovación antes y que a esa altura no sólo varió su discurso temático, sino también, y de manera profunda, sus conceptos técnicos y formales. Paralelamente a los cambios señalados y, quizá motivados los escultores por llevar su obra a los espacios de circulación de la pintura, se produce una drástica reducción de la escala monumental de la obra escultórica. Como señala Maderuelo (1994, p. 29), "con ello intentaban los escultores que sus obras fueran también bienes coleccionables, procurando atraer a los compradores de medianos recursos, aquellos que coleccionaban pintura". Con la pérdida de la monumentalidad, las obras resienten la exigencia de contexto y espacialidad que había tenido el monumento público. En consecuencia, la obra puede ser transportada, reubicada en cualquier sitio, interior o exterior, al igual que los cuadros. Considerando esta afinidad entre la pintura y la escultura, relativas al tamaño y la circulación, no resulta extraño que una buena parte de la escultura universal de los inicios del siglo XX esté escrita con nombres de pintores: Picasso, Miró, Matisse, Ernst, entre otros.

\section{Los primeros escultores innovadores en Chile}

Varios fueron los escultores que marcaron un acento diferente respecto de los modelos tradicionales que se habían instaurado en el país durante la segunda mitad del siglo XIX. Ernesto Concha, el autor de La miseria y Rebeca Matte generaron en su momento visiones distintas tanto en lo temático como en el lenguaje escultórico. Fueron estos autores los primeros en desmarcarse de los paradigmas decimonónicos.

Algunos elementos formales de la escultura moderna ${ }^{20}$ provenientes del viejo continente comienzan a formar parte en el discurso de los artistas locales durante la primera mitad del siglo XX. Los campos texturales insertos en determinadas obras

${ }^{20}$ Entenderemos como "escultura moderna" a las producciones plásticas que se manifestaron principalmente en la primera mitad del siglo XX, obras que emergen de algunos de los trabajos realizados entre 1880 y 1905 por autores tales como Augusto Rodin (Mujer agachada, de 1880-1882), Aristide Maillol (Acción encadenada, torso 1905), Henri Matisse (El ciervo, 1900-1903) y otros que señalaron la existencia de nuevos lenguajes para la expresión escultórica. 
de Rodin, tales como Mignon (bronce, 1870), El pensador (bronce, 1881) y Eva (bronce, 1881), se encuentran reinterpretados en algunas obras de Rebeca Matte, entre ellas Icaro y Dédalo. De forma semejante se nos presentan interesantes correlaciones en el aspecto que la escultora chilena da a la expresión de las carnaciones realizadas en metal. En este sentido se aprecian transferencias sígnicas no menores, visibles en las obras Crudo invierno -escultura que, a decir de Isabel Cruz (2008, p. 252), muestra a un anciano que se niega a entregarse a la edad que se adviene implacable para él-, como también en los cuerpos masculinos de Icaro y Dédalo.

Los cambios más radicales en la escultura nacional se generan bien avanzado ya el siglo XX. Enrique Melcherts (1982, p.131) señala que con la generación de Tótila Albert, José Perotti y Lorenzo Domínguez se produce la renovación más profunda en el arte estatuario chileno. "Desde el realismo de buena ley, modelado en formas robustas y quietas, que se aplica preferentemente a la búsqueda de la belleza plástica, se llega casi sin transición al modernismo tímido de estos tres maestros". Estos tres escultores enlazan la tradición estatuaria decimonónica con las nuevas formas escultóricas. Víctor Carvacho (1983, p. 223), por su parte, releva a la figura de Abelardo Bustamante (1888-1934), escultor y, sobre todo, pintor a quien se vincula con la conocida generación de 1913. Bustamante, que es considerado por Carvacho como el primer escultor moderno de formación culta, tuvo contacto con las corrientes artísticas europeas, especialmente con las alemanas. Su obra más conocida, de su no muy abundante producción en el arte del volumen, es Maternidad (Museo Nacional de Bellas Artes), una escultura de pequeño formato, en madera, impactada fuertemente por el cubismo. Esta obra evidencia vínculos con los volúmenes realizados por Otto Gutfreund (1889-1927), especialmente con sus cabezas cubistas realizadas entre 1911 y 1913, como también con Cabeza de mujer (Fernande) de Pablo Picasso (1909) ${ }^{21}$.

\section{Tótila Albert (1892-1967)}

Aun cuando nacido en Santiago, su vinculación con la escuela alemana fue significativa ${ }^{22}$. Entre 1915 y 1923 permanece en Berlín. En 1917 estudia con Franz Metzner (1870-1919), en la Academia de Bellas Artes de esa ciudad alemana. Europa en esta época está cruzada por los efectos de la guerra y, en el plano de las ideas estéticas, impactada también por la voz demandante de las vanguardias. En el terreno de la escultura el debate se plantea entre dos concepciones diferentes: el modelado y la talla directa. Albert opta por la segunda. A su regreso al país desarrolla una obra valiosa, tanto en el terreno creativo, como en el espacio académico. Llega y expone en el país en 1923, cuando el debate generado por los pintores del grupo Montparnasse, en la polémica exposición que habían realizado en la sala Rivas y Calvo, aun no se cerraba. Por tal razón y atendiendo, además, a los visos de modernidad que

\footnotetext{
${ }^{21}$ Los enlaces para este caso son dados no por la semejanza de lo representado, sino más bien por el tratamiento que Bustamante realizó con los volúmenes. Primeramente la figura de una mujer sosteniendo en sus brazos a un pequeño se encuentra "atada" al bloque de madera, es decir existe una sujeción importante entre los volúmenes que expresan los caracteres de la figura, los cuales al mismo tiempo se atan fuertemente al material constructivo. De esta forma lo tectónico tiende a dominar la figuración. En segundo orden, el acto de visión simultánea planteado por el cubismo analítico y sintético no tiene presencia en la obra de Bustamante, en este caso la figura se encuentra más bien "geometrizada" y crea con ello formas que aluden a lo "cúbico". En ello sí aparece el principio reduccionista, tan religiosamente buscado por las tendencias del arte, el diseño y la arquitectura de comienzos del siglo XX.

${ }^{22}$ Fue a Alemania en 1903 y regresa al país en 1912, estudiando inicialmente agricultura en Santiago.
} 
evidenciaba la obra del escultor no resultó extraño que sus obras fueran calificadas, cuando se expusieron en la Casa Eyzaguirre, al menos, como desconcertantes. "A aquella bullada exposición del grupo Montparnasse, que nuestro público la tomó y discutió impropiamente como cubista, sigue ahora la de un escultor chileno que ha obtenido grandes triunfos en Alemania, sede de los grandes escultores modernos" ${ }^{\prime \prime 2}$. Albert es, quizá, quien instala en nuestro país el primer gran debate en torno al arte del volumen. "En realidad, es la primera vez que se presenta al gran público, en el cual va a provocar violentas reacciones, pues entre todas las tendencias avanzadas, la de este artista es la más audaz"24. Joaquín Edwards Bello lo califica como un fauve, un vanguardista de Berlín. Si algo produce rabia en esta tierra, desgraciadamente, es la personalidad, la originalidad. Aquí queremos nivelarlos a todos: no admitimos en ninguna forma, los erizados, los que descuellan, los que salen de lo vulgar ${ }^{25}$. Eduardo Barrios también sumó su voz en defensa del joven escultor: "Gracias a la genialidad de un artista libre, esta vez no se repite esa degeneración azucarada con la cual se ha estado coimeando de trivialidad un siglo"26. Frente a los nostálgicos de la estética dieciochista, que reclamaban un realismo más ceñido a la verdad, la obra de Albert, sin duda, resultaba ajena a los preceptos establecidos y aceptados. La muestra del grupo Montparnasse y, luego, la exposición de Albert escenifican en nuestro medio un debate que en Europa tenía ya años de historia. En él se alineaban no sólo los artistas, sino también las voces teóricas, los medios y la sociedad influyente.

Albert fue autor de una producción artística numerosa. Dentro de sus obras más relevantes señalamos el Monumento a José Enrique Rodó. La escultura marca en nuestro medio una innovación respecto del tradicional monumento público, de carácter conmemorativo. La obra, licitada en 1942, fue inaugurada en 1944, cuando las viejas polémicas no amainaban. En una nota aparecida el 9 de octubre de ese año, en El Chileno (cuyo pie de firma es L.D.Z) se habla del pobre señor Rodó. El articulista se queja de la desilusión que le provocó la obra: pero no fue chica la sorpresa y grande la desilusión al encontrarnos que dista mucho de ser estatua y mucho más de ser Rodó. El periódico, El Chileno, había atacado la obra ya con motivo de la adjudicación del proyecto al escultor ${ }^{27}$. Frente a la fuerte crítica, otras voces, tales como Alberto Ried, Andrés Sabella y Roberto Meza Fuentes, entre otros, hablaron del monumento como una obra de arte ${ }^{28}$.

El discurso escultórico de Albert quebraba en Chile la norma académica y el tradicional lenguaje del monumento público. El alargamiento que el escultor chileno realiza de la figura humana, sin que ella pierda sus características descriptivas de musculatura

\footnotetext{
23 "La exposición de Tótila Albert" Los tiempos, Santiago de Chile, 10 de diciembre de 1923.

${ }^{24}$ Meléndez, L. "Tótila Albert" (Bellas Artes), La Nación, Santiago, 11 de diciembre de 1923.

${ }^{25}$ Edwards Bello, J., “Greguerías", Los tiempos, Santiago, 13 de diciembre de 1923.

${ }^{26}$ Barrios, E., “Un monumento a nuestro espíritu”, La Nación, Santiago, 15 de junio de 1924.

${ }^{27}$ Hay dos artículos que titulan "¿Cómo se pudo premiar a un mamarracho que pretende ser monumento a Rodó?" (21 de abril de 1942) y el otro "La logia de los 'monopolizadores del arte' explota al Fisco y se ríe del público" (24 de abril de 1942). ${ }^{28}$ Otro proyecto concursado en 1943, que homenajeaba al poeta nicaragüense Rubén Darío, fue adjudicado al escultor Raúl Vargas. Los jurados, entre los que formaron parte, el rector de la Universidad de Chile, Juvenal Hernández, Amanda Labarca, Fernando García Oldini, Carlos Humeres, Julio Barrenechea y los pintores Juan Martínez y Pablo Burchard, optaron esta vez por una obra de innegable débito neoclásico, una figura praxitélica emplazada actualmente en el Parque Forestal, de nuestra capital.
} 
y estructura ósea, lo une al trabajo del artista alemán Wilhelm Lehmbruck ${ }^{29}$, especialmente en obras tales como Joven de pié, que Lehmbruck realizara en piedra en 1913 y que, actualmente, se encuentra en The Museum of Modern Art de Nueva York. Otras obras de Albert, tales como Himno, Río eterno 2 y 3, La tierra y el propio Monumento a Rodó, traducen un vínculo formal con Lehmbruck. Estos conexos se evidencian en tres aspectos: a) la presencia de una estilización en donde la narrativa de la obra no pierde su capacidad de presentar los rasgos que describen cabezas, extremidades y torsos, b) algunos procesos de síntesis especialmente manifestados en seccionales menores del cuerpo humano, como dedos y aspectos faciales, y c) una morbideza en la discursividad de las volumetrías circulares extendidas, especialmente dadas en la expresión de los muslos.

\section{José Perotti (1898-1956)}

Escultor, pintor, ceramista y teórico del arte fue este artista, a quien nuestra historiografía vincula al grupo Montparnasse. Perotti da sus primeros pasos en la escultura junto al maestro Virginio Arias. Al igual que otros artistas de su época, parte de su formación la realiza en Europa. Perotti estuvo de 1920 a 1921 en España, en la Real Academia de Bellas Artes de San Fernando, en donde se vincula al escultor Miguel Blay. Luego parte a París, estudiando en la Academia Colarossi y en la Academia de la Grande Chaumiere, recibiendo lecciones de Antoine Bourdelle. De regreso a Chile, en 1923, se integra al grupo Montparnasse, formando parte activa de las nuevas concepciones estéticas que impactan la escena estética local. Por esta época se hace cargo de la cátedra de escultura en la Escuela de Bellas Artes, reemplazando a Simón González y ocupa este cargo hasta el conflictivo año de 1928. En 1929 fue nombrado como Director de la Escuela de Artes Aplicadas de la Universidad de Chile, de la cual fue prácticamente su creador. Entre 1937 y 1938 está en Alemania, haciendo uso de una beca Humboldt. Su tercer y último viaje, realizado entre 1942 y 1943, fue a Estados Unidos, llevando una exposición de arte chileno contemporáneo ${ }^{30}$.

Este artista, que obtuvo el Premio Nacional de Arte en 1953, se nos presenta como un creador polifacético. Su obra, de amplio espectro creativo, va de la pintura y la escultura a las artes aplicadas. A decir de Melcherts (1982, p. 141), "se aprecia en su obra una tendencia a las formas amplias, al sintetismo fuertemente estructurado en planos libres, que con frecuencia se inclinan hacia una decidida voluntad de belleza". En París, Perotti había recibido influencias de Rodin, a través de su discípulo Bourdelle. Después de haber hecho un proceso consciente de separación de estos maestros europeos, Perotti muta a un lenguaje más personal. A decir de Melcherts (1982, p. 141), "las formas se aflojan, el desnudo femenino -su permanente preocupacióndeja de ser la academia fría, rigurosa, serena y se desplaza en formas que por veces semejan vegetales marinos o formas rocosas a orillas del océano". De esta concepción surgen algunas de sus obras más importantes, entre ellas Sugerencia humana de las

${ }^{29}$ Wilhelm Lehmbruck, 1881-1919, Estudió en la Escuela de Artes Aplicadas de Dusseldorf, en su obra se funden algunos aspectos relacionados con el naturalismo y el expresionismo en estado de pasividad. La figura humana ocupa un lugar preponderante en su obra.

${ }^{30}$ José Perotti fue Commissioner General of the Exhibition of Chilean Contemporary Art and Special Representative of the Faculty of Fine Arts, University of Chile. La muestra se denominó Chilean Contemporary, Art Exhibition, The Toledo Museum of Art. 
rocas, Narciso, y Bote, quizá su obra más conocida. En esta obra de terracota las figuras humanas se muestran estilizadas, ello mediante un alargamiento que iconiza de forma muy parcial las formas musculares y óseas del cuerpo masculino y femenino. Esta solución plástica recuerda algunos de los aspectos que caracterizan el lenguaje de Alberto Giacometti. Está claro que ello no ocurre en las texturas que recubren sus figuras, sino más bien en el sentido de fragilidad y una presencia exigua; como si el espacio envolvente exhortara a la figura, comprimiéndola hasta reducirla a lo mínimo relevante para su existencia. Camilo Mori, pintor y cófrade generacional del escultor, refiere el siguiente comentario acerca de la obra de Perotti,

parece perpetuarse en el concepto de no crear volúmenes, sino, por el contrario, crear espacios. Pero, inquieto o insatisfecho, da por conocida o realizada esa su concepción, y parte nuevamente, siempre apoyándose en las formas naturales, hacia una nueva aventura. Es entonces cuando crea composiciones que podríamos llamar; en contraposición a las vegetales, pétreas. Ahora son las rocas, como antes las algas, observadas en sus días de vacaciones en la costa, las que los inspiran y seducen. Vuelven de nuevo los volúmenes a adquirir jerarquía y a ser dominantes. Las oquedades, como gustaba llamar los vacíos expresivos de sus creaciones vegetales han dado paso a otras que juegan sólo para animar con claroscuro las grandes masas petrificadas de sus últimas concepciones, en las han desaparecido las aparentes similitudes de lo que en un momento de su labor pudo estimarse influencia del inglés Henry Moore ${ }^{31}$.

\section{Lorenzo Domínguez (1901-1963)}

Nacido en Chile, sus primeros años de estudio transcurren en España, en donde cursa la carrera de medicina, la que abandona para dedicarse a su verdadera vocación: el arte. Sus primeros pasos en la escultura lo vinculan a algunos importantes artistas peninsulares, entre ellos Juan Cristóbal (escultor vallisoletano con quien se inicia en la talla directa), Emiliano Barral y Victorio Macho, quizá el artista que mayor impacto tuvo en su obra. Antes de regresar a Chile, en 1930, está por algún tiempo en París. En Santiago le espera un escenario artístico -al menos en el plano escultórico- todavía muy vinculado al naturalismo academicista. El tradicional monumento público, pedestal incluido, era todavía el argumento de desarrollo y legitimidad de los artistas locales. En 1931 fue nombrado profesor de escultura en la Facultad de Bellas Artes, cargo que desempeñó hasta 1941. Según Ernesto Muñoz (2010, p. 196), "su ingreso en la Escuela de Bellas Artes de Santiago no podía ser neutro; traía una experiencia personal demasiado intensa como para que no se notara. Inmediatamente ordenó la enseñanza de la escultura y promovió la talla directa como método de creación escultórico que vinculaba a los alumnos con los verdaderos problemas del material. Atrás quedaban los ya inertes sistemas pedagógicos basados en el modelado, vaciado y traspaso de puntos. A decir de Víctor Carvacho (1983, p. 216), ha hecho ver con claridad dónde residen los problemas medulares del trabajo del escultor y de la expresión del artista". En 1938 viajó nuevamente a Europa. Está por algo menos de un año en Barcelona, trabajando y colaborando con los republicanos en la restauración de monumentos públicos. Luego viaja a París, tomando contacto con los maestros más importante de la época, entre ellos Bourdelle. Le interesa, además, la obra de

${ }^{31}$ Mori, Camilo, “Trayectoria de José Perotti", Revista de Arte No 4, junio-julio 1956, Santiago de Chile. 
Malliol, Despiau, Mestrovic y Brancusi. Regresa a Chile y, a partir de 1941, se vincula con la Escuela de Bellas Artes de la Universidad de Cuyo, en Mendoza. Entre 1931 y 1941 fueron los años más fecundos en nuestro país. De esa época son sus numerosas cabezas femeninas y masculinas, caracterizadas por un fuerte expresionismo ${ }^{32}$. Se trata de cabezas de estilo monumental, concebidas para ser puestas al aire libre. Según Diego Pro $(1965$, p. 69) la concepción de monumentalidad en estas obras lleva a la construcción, la construcción a la simplificación y la simplificación a la geometrización. Se suman a este concepto sus bustos y torsos, además de algunos monumentos, como el de Ramón y Cajal, realizado en España ${ }^{33}$, obra ésta que recuerda la estética de Victorio Macho. En Chile, su escultura más importante quizá sea el Homenaje al Dr. Calvo Mackenna (1941, piedra azul, Parque Balmaceda de Santiago). Según Carvacho (1983, p. 217), esta obra tiene una potente y sensual afirmación del volumen, el que se derrama, sobre el aire que lo envuelve, la majestad soberana de su grandeza, tanto como la criatura que surge de entre los muslos matroniles expresa el misterio de la fecundidad plena. Otro tema que lo obsesiona es el arte escultórico de la Isla de Pascua ${ }^{34}$. Esta preocupación por lo ancestral, en este caso por esta cultura insular, lo llevan a una valoración de lo propio, actitud que vemos también en otros autores, entre ellos Laura Rodig y Marta Colvin, que incorporan en su obra formas escultóricas que hacen referencia a elementos iconográficos de carácter americano. En 1956 el maestro está nuevamente por algún tiempo en nuestro país. La obra global de Domínguez destaca por su creación artística y por su labor docente. Fallece en Mendoza, en mayo de 1963.

\section{Samuel Román (1907-1990)}

Entre 1924 y 1928 estudió en la Escuela de Bellas Artes de la Universidad de Chile. Su primer maestro fue Carlos Lagarrigue. Luego conoce y se cambia a la cátedra de Virginio Arias, maestro más complejo de trato, bajo cuya orientación se habían formado varios importantes escultores nacionales. A comienzos de 1937 le es concedida, junto a Israel Roa y José Perotti, la beca Humboldt, que le permite cursar estudios en Alemania, en la Academia de Bellas Artes de Berlín, hasta 1939. En julio de 1937 viaja junto a Roa a París. "Días enteros estuvimos absortos, silenciosos, junto a las obras de Miguel Ángel; en las salas de arte griego, o del arte egipcio, o gótico... ${ }^{35}$. En el Petit Palais pudo admirar los artistas modernos: Para mí Maillol es el más valioso, por su contribución a la plástica de hoy"36. Según Eugenio Pereira Salas, que por esta época visita Berlín, en Román la raza brota a raudales, "en Bourdelle encuentra la honestidad de la materia; en Giess y en Wladschmidt, la forma nueva para los viejos ideales" ${ }^{\prime 37}$.

\footnotetext{
${ }^{32}$ Sus trabajos más conocidos a este respecto son la cabeza de Pablo Burchard (1936), Augusto D’Almar (1937), Lilión (1937) y Alejandro Lipschutz (1937).

${ }^{33}$ En 1928 ganó un concurso para realizar este monumento. De esa experiencia tomó la determinación de dejar definitivamente los estudios de medicina para dedicarse de lleno a la escultura.

${ }^{34}$ Domínguez recorre la Isla dibujando y fotografiando las obras de mayor interés. Según señala Ernesto Muñoz, el material acumulado dará origen a un libro que se edita cinco años después de su muerte en Buenos Aires. La obra se tituló Las esculturas de la Isla de Pascua, Ediciones de Fondo Nacional de las Artes, Buenos Aires, 1968.

${ }^{35}$ Héctor Román, “La vida y la obra del escultor chileno Samuel Rojas Román”, Memoria para optar al título de Profesor de Artes Plásticas, Facultad de Artes de la Universidad de Chile, Santiago de Chile, 1959, p. 53.

${ }^{36}$ Román, H., p. 53.

${ }^{37}$ Román, H., p. 59.
} 
En abril de 1946 inaugura el Monumento a las educadoras Isabel Lebrun y Antonia Tarragó (Alameda Bernardo O'Higgins de Santiago), una de sus obras emblemáticas. Se trata de una escultura que en su momento generó polémica. Entre las voces que estuvieron a favor de la instalación de la obra estuvo Marco A. Bontá, Director del Museo de Arte Contemporáneo de Santiago, quien señaló; he visto el proyecto y las dos figuras esculpidas de tamaño definitivo en granito, en talla directa. "Mi opinión es que este monumento será el mejor que tendrá la ciudad de Santiago, si el mal criterio no se opone" ${ }^{\prime \prime 38}$. Antonio Romera, por su parte, señaló: "dos inmensos bloques de la cordillera han sido devastados por el enérgico cincel de Samuel Román. La piedra noble aparece aquí en toda su grandeza, dignificada por el soplo del arte" ${ }^{\prime \prime 39}$.

Hay un par de obras más que es necesario apuntar como las esculturas más significativas de este autor. Se trata del Monumento al Presidente Balmaceda, ejecutado en bronce el año 1949; y el Monumento a Enrique Molina Garmendia, realizado en 1966 en la Universidad de Concepción.

Samuel Román dejó una extensa obra para la historia de la escultura en Chile. En ella se aprecian vínculos con distintos escultores europeos. A modo de ejemplo, la terracota modelada en 1937 titulada Olimpíada, que representa un desnudo femenino de pie, tiene cierto nivel de coincidencia con algunos desnudos de Aristide Maillol, artista que, junto a Rodin, es considerado uno de los fundadores de la escultura moderna. Otras obras de Román, tales como el rostro de Esther (1936), Anayansi (1930), y las cabezas de Las educadoras (1949), además de unirlo a ciertas geometrías brancusianas ${ }^{40}$ -evidenciadas en obras como Mademoiselle Pogamy, de 1912 y La musa dormida del mismo año- también lo vinculan con el escultor argentino Alfredo Bigatti (1898-1964), artista que desarrolló su trabajo entre 1920 y 1960. La obra titulada Alba (piedra, 1935) puede incluirse en esta línea de trabajo plástico. Se debe agregar a lo anterior, otros reduccionismos geométricos de Román, también presentes en la escultura Art Decó inscritas en las edificaciones en altura de los años treinta y cuarenta del siglo XX.

La obra de Román define también un conexo con la obra de Henry Moore. Resulta difícil no vincular, a modo de ejemplo, la obra La segadora (colección particular), del autor chileno, con un par de figuras reclinadas que realizó el escultor inglés ${ }^{41}$. Román se interesó también por la cerámica y las artesanías, expresiones que, en distintos momentos, se integran a su labor de escultor. En este interés por lo vernáculo podemos colegir una puesta en valor de sus ancestros culturales e iconográficos. Advertimos ello también en su labor docente, especialmente aquella desarrollada en la Escuela de Canteros, entidad que funda en 1943 y que estuvo destinada a perfeccionar artesanos en la talla y labra de la piedra.

\footnotetext{
${ }^{38}$ Román, H., p. 98.

${ }^{39}$ Román, H., p. 98.

${ }^{40}$ Entenderemos como "geometrías brancusianas" a una parte del lenguaje desarrollado por Constantin Brancusi para la expresión de los rostros creados en las primeras décadas del siglo XX. En esta fase del artista rumano, en donde la actividad de purificar la forma, tema que comenzó con su admiración y ejecución de obras basado en el arte africano, lo llevó a desarrollar algunas síntesis que geometrizaron los caracteres del rostro humano, especialmente notorios son los ojos tratados con forma de huso desde el cual emerge el globo ocular, su fisonomía se muestra como una sección adscrita a un ovoide. Los trabajos mencionados de Samuel Román, como los de Alfredo Bigatti, emergen de esta circunstancia y cobran fuerza en la estética individual de cada uno de ellos.

${ }^{41}$ Figura reclinada (1929), piedra, Leeds, Leeds City Art Gallery. Figura reclinada, Ottawa, Nacional Gallery of Art, Canadá.
} 
Otros escultores suman su obra a los procesos de innovación de la escultura chilena. Entre ellos Laura Rodig (1901-1972), artista que se vincula a Gabriela Mistral. Juntas emprenden un viaje a México, quedando la escultora marcada por el arte mejicano, especialmente por el muralismo. De ahí un arte marcado por un "ethos" americanista, como el que evidencia su Maternidad, del Museo Nacional de Bellas Artes de nuestro país. Marta Colvin (1907-1995), vinculada, en su formación, con importantes maestros europeos, entre ellos Henri Moore y Ossip Zadkine, desarrolla una importante labor docente en la Escuela de Arte de la Universidad de Chile. Su obra creativa se plantea a partir de renovados argumentos formales e iconográficos. Lily Garáfulic (1914), discípula de Lorenzo Domínguez, es otra de las artistas que destacan, hasta nuestros días, en el panorama de la escultura chilena.

A la nómina señalada es preciso agregar los nombres del español Claudio Tarragó, Abelardo Araya, destacado por Carvacho como uno de los grandes innovadores de la escultura chilena, Manuel Banderas Domarchi, Guillermo Mosella, Peter Horn, María Fuentealba, Rosa Vicuña, María Teresa Pinto, María Isabel Sotomayor, Sergio Mallol, Abraham Freifeld, Claudio Girola, entre varios otros.

\section{Referencias bibliográficas}

Barrios, E., “Un monumento a nuestro espíritu” La Nación, Santiago, 15 de junio de 1924.

Bénézit, E. Dictionnarie critique et documentaire des Peintres Sculpteurs Dessinateurs et Graveurs, Nouvelle Édition, Grund, París 1999, Tomos 1 al 14.

Carvacho, V., Historia de la escultura en Chile, Editorial Andrés Bello, Santiago de Chile, 1983.

Canseco-Jerez, A., La vanguardia chilena Santiago-París, ACJB Editions, París, Francia, 2001.

Cruz de Amenábar, I., Manos de mujer: Rebeca Matte y su época (1875-1929), Ediciones Origo, Santiago de Chile, 2008.

Edwards Bello, J., “Greguerías”, Los tiempos, Santiago, 13 de diciembre de 1923.

Hegel, W. F., Estética, “La arquitectura y la escultura” Ediciones Nueva Visión 1985.

Hobsbawn, E., A la zaga: decadencia y fracaso de las vanguardias del siglo XX, (1998) Crítica, Egedsa Barcelona España, 2009.

Ivelic, R., "Escultura chilena e identidad (1900-1970)", Revista Aisthesis Instituto de Estética de la Pontificia Universidad Católica de Chile, No 34 , Santiago de Chile, 2001. 
“La exposición de Tótila Albert", Los tiempos, Santiago de Chile, 10 de diciembre de 1923.

Letelier, R. y otros, Artes plásticas en los Anales de la Universidad de Chile, Museo de Arte Contemporáneo, 1993.

Lewinson, J., Henry Moore, Taschen, Koln, Alemania, 2007.

Mackenna Subercaseaux, A., Luchas por el arte, "El origen del Museo de Copias", conferencia en el Ateneo de Santiago, Sociedad Imprenta-Litografía Barcelona, Santiago-Valparaíso, 1915.

Maderuelo, J., La pérdida del pedestal, Círculo de Bellas Artes, Madrid, 1994.

Melcherts, E., Introducción a la escultura chilena, Colegio Regional de Periodistas A. G. y Círculo de Prensa de Valparaíso, Chile, 1982.

Meléndez, L., "Tótila Albert" (Bellas Artes), La Nación, Santiago, 11 de diciembre de 1923.

Mistral, G., Escultura de Marina Núñez del Prado, Ediciones Galería Bonino, Buenos Aires, Argentina, 1991.

Mori, C., “Trayectoria de José Perotti”, Revista de Arte No 4, junio-julio 1956, Santiago de Chile.

Muñoz, E., La modernidad extraviada, Ediciones AICA Chile, Santiago de Chile, 2009.

Pro, D., Tiempo de piedra Lorenzo Domínguez, Talleres Gráficos D’Accurzio, Mendoza, Argentina, 1966.

Règlement Ècole Nationale des Beaux - Arts, Ministère de L'Instruction Publique des Beaux - Arts et des Cultes, Delalain Frères Èditeurs, París, 1908.

Román, H., La vida y la obra del escultor chileno Samuel Román (hasta el año 1959), Memoria para optar al título de Profesor de Artes Plásticas, Facultad de Bellas Artes de la Universidad de Chile, Santiago de Chile, 1959.

Sauras, J., La escultura y el oficio de escultor, Ediciones del Serbal, Barcelona, España, 2003.

Souriau, E., Diccionario de Estética, Ediciones Akal, 1998.

Wittkower, R., La escultura: procesos y principios, Alianza Forma, Madrid, 2006. 